\section{Effectiveness of Colchicine and Oryzalin at Inducing Polyploidy in Watsonia lepida N.E. Brown}

\author{
Glendon D. Ascough and Johannes van Staden ${ }^{1}$
}

Research Centre for Plant Growth and Development, School of Biological and Conservation Sciences, University of KwaZulu-Natal Pietermaritzburg, Private Bag X01, Scottsville, 3201, South Africa

\section{John E. Erwin \\ Department of Horticultural Science, University of Minnesota, 1970 Folwell Avenue, St. Paul, MN 55108}

Additional index words. flow cytometry, Iridaceae, tetraploid, mixoploid, chromosome doubling, bugle lily

\begin{abstract}
Genetic modification and manipulation offers the possibility of introducing novel traits into existing plants, thereby increasing marketability. Polyploid induction has in the past produced plants that are more compact and have larger flowers, leaves, and fruit, making them more desirable to consumers. The effect of pulse treatments $(0$, $24,48$, and $72 \mathrm{~h})$ of colchicine $(25,50,125$, and $250 \mu \mathrm{M})$ or oryzalin $(30,60,90$, and $120 \mu \mathrm{M})$ on in vitro-grown Watsonia lepida N.E. Brown shoots was investigated. Explant survival was higher and more consistent with oryzalin treatment compared with treatment with colchicine. More mixoploids than tetraploids were produced with both compounds. The optimum treatment for producing tetraploids was $120 \mu \mathrm{M}$ oryzalin for $24 \mathrm{~h}$. Of the $30 \%$ explants that survived this treatment, $33 \%$ were found to be stable tetraploids.
\end{abstract}

Sexual reproduction results in the fusion of two gametophytes ( $n$ ) to form a new sporophyte (2n) zygote containing genetic material from both parents. It is possible that over extended periods of time, mutations, discrepancies in reduction division during gamete formation, spontaneous somatic polyploidization, and wide hybridization cause plants to accumulate additional sets of chromosomes from closely or distantly related species. Polyploidy has been an important factor in plant evolution and is often associated with speciation and development of novel adaptations (Levin, 2002). Approximately $70 \%$ of all angiosperms are considered polyploids (Goldblatt, 1980; Masterson, 1994).

It is possible to artificially create polyploid plants by interfering with cell division. A number of natural and synthetic compounds can be used and are either applied to plants ex vitro or in vitro. Colchicine is naturally occurring, and it was initially thought that it promoted polyploidy induction by disrupting spindle formation and preventing nuclear and cell division (Ganga and Chezhiyan, 2002, and references therein).

\footnotetext{
Received for publication 17 July 2008. Accepted for publication 13 Aug. 2008.

We are grateful to the National Research Foundation, Pretoria, and the University of Minnesota Agriculture Experiment Station and the Minnesota Nursery and Landscape Foundation for generous financial assistance.

${ }^{1}$ To whom reprint requests should be addressed; e-mail rcpgd@ukzn.ac.za
}

Recently, however, Caperta et al. (2006) showed that spindle disruption alone is insufficient for the production of polyploid cells. Low concentrations $(0.5 \mathrm{~mm})$ of colchicine inhibited microtubule formation in all phases of the cell cycle but resulted in abnormalities, including reduced viability from irregularshaped nuclei and micronuclei. In contrast, treatment with high concentrations $(5 \mathrm{~mm})$ of colchicine induced microtubule polymerization to form new structures in c-metaphase cells. These new structures are thought to aid reconstitution of polyploid nuclei and subsequent re-entry into the cell cycle (Caperta et al., 2006). Oryzalin and trifluralin are synthetic herbicides used for weed control and disrupt microtubule assembly during cell division. They are often more effective than colchicine because they have a higher affinity for plant tubulins (Dolezel et al., 1994).

Effectiveness of these compounds in vitro depends highly on the concentration applied, penetration of the compound (Allum et al., 2007). Colchicine has been effectively used in the concentration range $0.25 \mu \mathrm{M}$ (Chen et al., 2006) to $38,000 \mu \mathrm{M}$ (Stanys et al., 2006); oryzalin from $2.5 \mu \mathrm{M}$ (Allum et al., 2007) to $150 \mu \mathrm{M}$ (Contreras et al., 2007); and trifluralin from $250 \mu \mathrm{M}$ to $2500 \mu \mathrm{M}$ (field application ex vitro; Zlesak et al., 2005). In many instances, oryzalin and trifluralin are more effective at stable ploidy induction, have an increased survival of explants, and are used at lower concentrations than colchicine (Ganga and Chezhiyan, 2002; Zlesak et al., 2005). duration of treatment, type of explant, and the
Ploidy manipulation offers some benefits for horticultural, pharmaceutical, and agricultural improvement of plants. Rhododendron tetraploids induced by oryzalin had larger leaves, flowers, and pollen compared with diploids (Contreras et al., 2007). Similarly, tetraploid watermelons had greater leaf area, larger flowers and ovaries, larger seeds, and a thicker rind (Jaskani et al., 2005). From a horticultural perspective, polyploid plants often have a shorter, more squat stature, and the larger, thicker leaves and bigger flowers are more attractive to consumers (Chen et al., 2006). Production of secondary metabolites from polyploid plants was increased in Panax ginseng (Kim et al., 2004), Artemisia annua (De Jesus-Gonzalez and Weathers, 2003), Datura stramonium (Berkov and Philipov, 2002), and Scutallaria biacalensis (Gao et al., 2002).

A number of explants can be used as starting material to induce polyploidy. Young, actively growing explants containing a meristem usually give best results. For example, success has been found using germinating seeds (Pringle and Murray, 1992), ex vitro shoots (Contreras et al., 2007), roots (Kim et al., 2004), embryogenic callus (Gmitter et al., 1991), nonembryogenic callus (Gao et al., 2002), nodal segments (Chen et al., 2006), cotyledons (Stanys et al., 2006), and hypocotyls (De Carvalho et al., 2005). During micropropagation of Watsonia species, we observed that only the hypocotyl region of seedlings (immediately above the root) was capable of regenerating adventitious shoots, probably because they contain the shoot apical meristem and thus would make suitable explants for ploidy induction (Ascough et al., 2007).

Stomata of induced polyploids are usually larger (Griesbach and Bhat, 1990; Kadota and Niimi, 2002), a simple diagnostic feature that is often used to identify potential polyploids. This technique is rapid, inexpensive, nondestructive, does not require sophisticated equipment, and has a fairly high accuracy rate (up to $90 \%$ in some cases; Cohen and Yao, 1996); however, it is an indirect method for ploidy assessment. If mixoploid plants are produced, then stomatal size can be an unreliable method and should be combined with another technique (Chen et al., 2006). Chromosome counts are perhaps the most accurate, and aneuploidy may be detected, although this method can be timeconsuming if many plants are being tested. Analysis of DNA content by flow cytometry is often preferred. Because many thousands of cells can be analyzed rapidly, mixoploids can be readily detected. In some cases, for example, in genome doubling from wide hybridization, genomic rearrangement can lead to altered genome size and complicate interpretation of ploidy based on DNA content (Levin, 2002). In addition, flow cytometry requires the purchase of expensive equipment, and chromosome behavior cannot be observed with this method.

The genus Watsonia Miller has several members that show potential for horticultural 
use. For instance, many of the species grow taller than $1 \mathrm{~m}$, and although this may be good for use in cut flowers, it is too tall for use as a container plant. In Watsonia aletroides (Burman fil.) Ker and $W$. meriana (Linnaeus) Miller, populations of triploid $(2 n=3 x=27)$ plants are known, but polyploidy has not otherwise been documented in the genus (Goldblatt, 1989). These triploids do not produce seeds, but produce axillary cormlets at the aerial nodes of the spike after flowering (Goldblatt, 1989). Although chromosome counts have not been performed on $W$. lepida, plants are assumed to be diploid $(2 n=2 x=18)$ because they produce seeds. The $1 \mathrm{C}$ value of $W$. laccata (Jacquin) Ker was determined as $0.7 \mathrm{pg}$ (Goldblatt et al., 1984).

Four species (W. gladioloides Schlechter, $W$. laccata, $W$. lepida, and $W$. vanderspuyiae L. Bolus) have been propagated in tissue culture (Ascough et al., 2007, 2008) and chemical dwarfing techniques have been successful on $W$. tabularis Mathews \& L. Bolus and Watsonia 'Shrimp pink' (Thompson et al., 2005). However, to maintain a dwarf stature, corms need to be retreated each year. Thus, the effectiveness of colchicine and oryzalin at inducing polyploidy in $W$. lepida was investigated to establish a working protocol for polyploidization in this genus. The long-term goal is to use polyploidy as a permanent means of dwarfing. Additional morphological change like altered flower phenotypes may also improve marketability of plants to consumers.

\section{Materials and Methods}

Plant material. Seeds from a single seed lot of $W$. lepida were obtained from Silverhill Nurseries, Kenilworth, South Africa, and the experiment initiated within 1 month of receiving the seeds.

Culture conditions. Except for seed germination in which one-tenth strength Murashige and Skoog (MS) basal salts (Murashige and Skoog, 1962) were used without sucrose or hormones, all media contained fullstrength MS components and 3\% sucrose $(\mathrm{w} / \mathrm{v})$. Medium $\mathrm{pH}$ was adjusted to 5.8 using $\mathrm{NaOH}$ before addition of $0.9 \%$ agar $(\mathrm{w} / \mathrm{v})$ (Agar-Agar no. 1; Marine Chemicals, Kerala, India) and sterilized by autoclaving at $121^{\circ} \mathrm{C}$ and $103.4 \mathrm{kPa}$ for $20 \mathrm{~min}$. All cultures were incubated at $25 \pm 1^{\circ} \mathrm{C}$ under Osram ${ }^{\circledR}$ (Johannesburg, South Africa) $75-\mathrm{W}$ cool white fluorescent tubes providing a 16-h photoperiod and a light intensity of $12.6 \mu \mathrm{mol} \cdot \mathrm{m}^{-2} \cdot \mathrm{s}^{-1}$ at culture level.

Seeds were decontaminated for $15 \mathrm{~min}$ in a $50 \%$ (by volume) commercial bleach [ $\mathrm{Jik}^{\circledR}$ (Reckitt Colman, Elandsfontein, South Africa), 3.5\% sodium hypochlorite] solution with three drops of Tween 20 as a surfactant. Seeds were rinsed three times with sterile distilled water, placed on a one-tenth strength MS medium, and transferred to the culture room for germination.

After 3 weeks, uniform seedlings $4 \mathrm{~cm}$ long were selected for experimental studies. The root and upper portion of the leaf were excised using sterile technique in a lamina flow bench, and sections $1 \mathrm{~cm}$ long, containing the hypocotyl and lower leaf, were used as explants. These explants were implanted vertically in media with their basal end in $65 \times 10-\mathrm{mm}$ petri dishes. Ten explants were placed in each petri dish. Media consisted of MS basal salts and either colchicine at a concentration of $0,25,50,125$, or $250 \mu \mathrm{M}$ or oryzalin [4-(dipropylamino)-3, 5-dinitrobenzenesulfonamide] at a concentration of $0,30,60,90$, or $120 \mu \mathrm{M}$. Both colchicine and oryzalin were purchased from SigmaAldrich (St. Louis, MO). Explants were removed after 24,48 , or $72 \mathrm{~h}$ and placed singly in cylindrical $33-\mathrm{mL}$ clear glass culture tubes containing $10 \mathrm{~mL}$ MS media with $2.2 \mu \mathrm{M}$ BA to promote shoot production (Ascough et al., 2007). Subculturing was not necessary because plants did not "outgrow" their culture tubes. Ten explants were used for each treatment, and the experiment was repeated twice (for oryzalin treatments) and four times (for colchicine treatments) in time.

After 3 months, explants were examined to determine percentage survival. The few explants that had become infected with microbial contaminants $(\approx 5 \%)$ or were necrotic as a result of the treatment were discarded. Those that had survived and showed signs of regeneration (elongation, rooting, or multiplication) were analyzed for ploidy level by flow cytometric analysis (Ascough et al., 2006). Leaf tissue samples $(0.3 \mathrm{~g})$ from plantlets were cut into very small pieces with a razor blade in $1 \mathrm{~mL}$ extraction buffer containing $100 \mathrm{~mm} \mathrm{MgCl} 2,40 \mathrm{~mm}$ trisodium citrate, $22 \mathrm{~mm} \mathrm{MOPS}$, and $0.1 \%(\mathrm{v} / \mathrm{v})$ Triton-X-100 with $\mathrm{pH}$ adjusted to 7.1. The suspension was filtered through a $50-\mu \mathrm{m}$ mesh filter and stained with $500 \mu \mathrm{L}$ propidium iodide for a final concentration of $0.5 \mathrm{~mm}$. Fluorescence was measured using a Beckman Coulter (Fullerton, CA) Epics XL-MCL flow cytometer and total DNA content was compared with control data from untreated in vitro diploid control plants.

Data analysis. Data on survival rate, proportion diploid, mixoploid, and tetraploid plants were arcsine-transformed before statistical analysis by analysis of variance using Minitab $^{\circledR}$ (State College, PA) release 14
Means were separated using Fisher's individual error rate at the $5 \%$ level of significance.

\section{Results and Discussion}

Lower concentrations and shorter durations of exposure to colchicine tended to have greater survival (Table 1). Best survival (84\%) was observed when explants were treated for the shortest time $(24 \mathrm{~h})$ at the lowest concentration $(25 \mu \mathrm{M})$. However, no polyploid plants were induced, and only diploids were observed, as indicated by the peak in the same position as the untreated control (Fig. 1A). A 48-h treatment at the same concentration resulted in moderate survival and no polyploids were produced. Only one explant treated for $72 \mathrm{~h}$ was mixoploid containing both diploid and tetraploid cells (Fig. 1B). A 24-h treatment at $50 \mu \mathrm{M}$ produced more mixoploids with moderate survival rates, but when the concentration or duration was increased, explant survival declined sharply (Table 1). No tetraploids were observed in any of the surviving colchicine-treated plantlets despite high frequencies of mixoploid induction occurring at $250 \mu \mathrm{M}$. It is possible that even the shortest duration was too long, and a shorter duration of 6 or $12 \mathrm{~h}$ may be more effective.

Most of the explants produced healthy shoots in vitro, but there was very little adventitious shoot production and hence a low multiplication rate. Explants producing multiple shoots were all found to be diploid (data not shown). It is uncertain if this low multiplication was the result of the treatment regime or simply a suboptimal multiplication procedure. In this study, the concentrations of colchicine used were much lower than those used by Caperta et al. (2006). However, these concentrations are consistent with most other published reports in which tetraploids were successfully created, for example, in Gladiolus (Suzuki et al., 2005), Scutellaria (Gao et al., 2002), and in Rhododendron (Väinölä and Repo, 2001).

A number of recent reports indicate oryzalin as an effective alternative to colchicine. It can be used as a potential replacement because it is safer to work with and, at least in

Table 1. Survival and ploidy level of Watsonia lepida plantlets regenerated from hypocotyl segments treated with colchicine.

\begin{tabular}{lccc}
\hline Treatment & Survival/treated $(\%)^{\mathrm{z}}$ & Diploid no. $(\%)$ & Mixoploid no. (\%) \\
\hline $0 \mu \mathrm{M}$ & $38 / 40(95) \mathrm{a}$ & $38(100) \mathrm{a}$ & $0(0) \mathrm{a}$ \\
$25 \mu \mathrm{M} 24 \mathrm{~h}$ & $26 / 38(84) \mathrm{b}$ & $26(100) \mathrm{a}$ & $0(0) \mathrm{a}$ \\
$48 \mathrm{~h}$ & $14 / 36(39) \mathrm{cdef}$ & $14(100) \mathrm{a}$ & $0(0) \mathrm{a}$ \\
$72 \mathrm{~h}$ & $20 / 38(53) \mathrm{bcde}$ & $19(95) \mathrm{ab}$ & $1(5) \mathrm{a}$ \\
$50 \mu \mathrm{M} 24 \mathrm{~h}$ & $22 / 36(61) \mathrm{bcd}$ & $19(86) \mathrm{abc}$ & $3(14) \mathrm{a}$ \\
$48 \mathrm{~h}$ & $10 / 36(28) \mathrm{ef}$ & $9(90) \mathrm{abcd}$ & $1(10) \mathrm{a}$ \\
$72 \mathrm{~h}$ & $12 / 36(33) \mathrm{def}$ & $11(92) \mathrm{abcde}$ & $1(8) \mathrm{a}$ \\
$125 \mu \mathrm{M} 24 \mathrm{~h}$ & $10 / 36(28) \mathrm{f}$ & $7(70) \mathrm{bcde}$ & $3(30) \mathrm{a}$ \\
$48 \mathrm{~h}$ & $9 / 36(25) \mathrm{f}$ & $7(78) \mathrm{abcde}$ & $2(22) \mathrm{a}$ \\
$72 \mathrm{~h}$ & $6 / 36(17) \mathrm{f}$ & $4(67) \mathrm{bcde}$ & $2(33) \mathrm{a}$ \\
$250 \mu \mathrm{M} 24 \mathrm{~h}$ & $8 / 36(22) \mathrm{f}$ & $5(62) \mathrm{e}$ & $3(38) \mathrm{a}$ \\
$48 \mathrm{~h}$ & $6 / 36(17) \mathrm{f}$ & $4(67) \mathrm{de}$ & $2(33) \mathrm{a}$ \\
$72 \mathrm{~h}$ & $5 / 36(14) \mathrm{f}$ & $4(80) \mathrm{cde}$ & $1(20) \mathrm{a}$ \\
\hline
\end{tabular}

${ }^{2}$ Values containing the same letter within a column are not significantly different from each other at the $5 \%$ level of significance. 

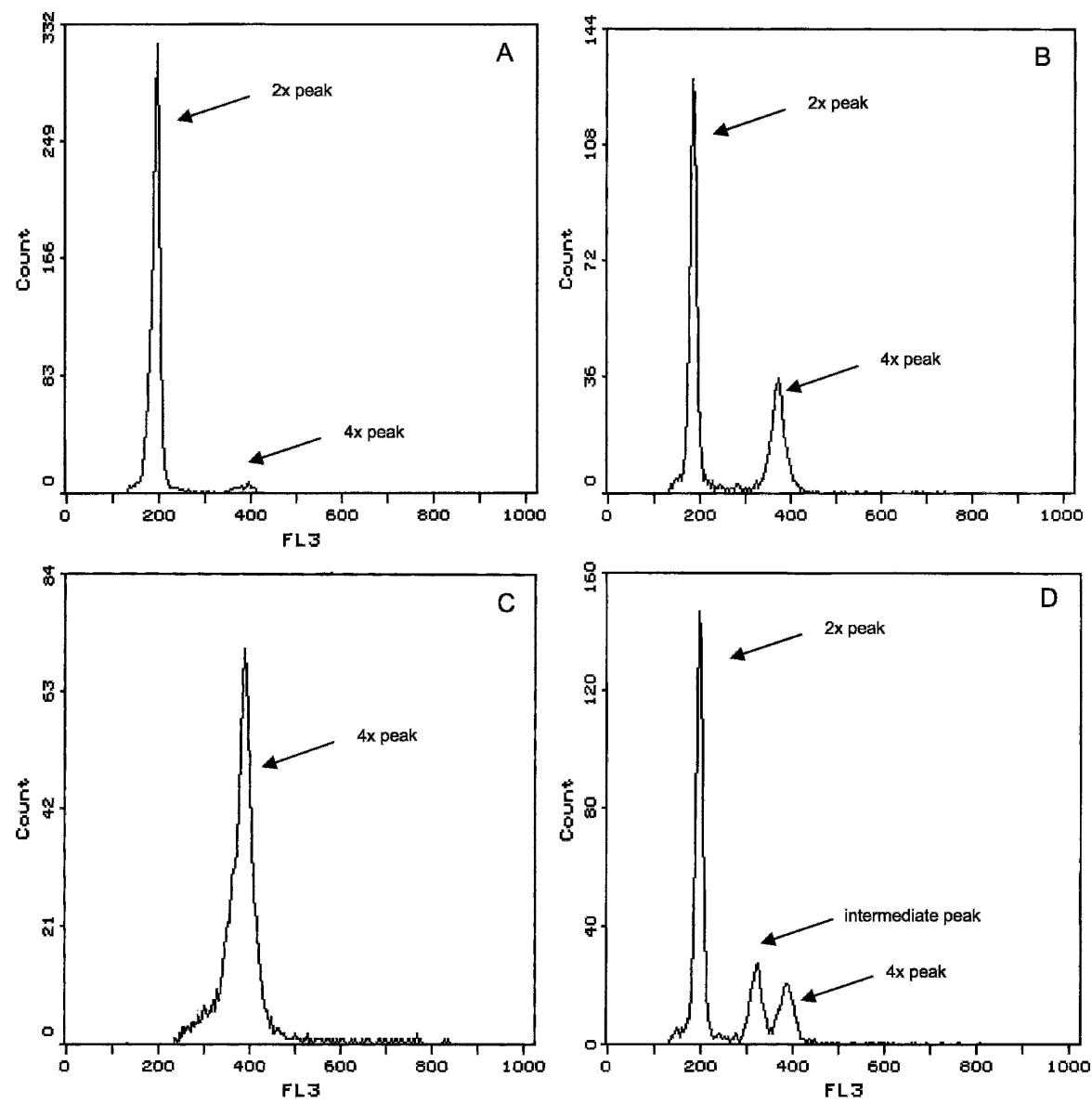

Fig. 1. Flow cytometry histogram of (A) an untreated (control) Watsonia lepida seedling. The diploid peak is set at channel 200, and the tetraploid peak (in this case, a small amount of cell division) is observed at channel 400; (B) a mixoploid $W$. lepida individual showing a large number of tetraploid nuclei in addition to the diploid peak; $(\mathbf{C})$ a tetraploid $W$. lepida individual. Note the single peak close to channel 400; (D) an unusual $W$. lepida seedling. Note that peaks occur at the diploid (channel 200), tetraploid (channel 400), and an intermediate peak (channel 330). X-axis is number of nuclei counted; $y$-axis is relative fluorescence intensity.

some species, plantlet survival and tetraploid induction are higher at a much lower concentration than with colchicine (De Carvalho et al., 2005). Survival of $W$. lepida hypocotyl explants treated with oryzalin for $24 \mathrm{~h}$ at the two lowest concentrations ( 30 and $60 \mu \mathrm{M}$; Table 2) was lower than that of the two lowest concentrations $(25$ and $50 \mu \mathrm{M})$ of colchicine

Table 2. Survival and ploidy level of Watsonia lepida plantlets regenerated from hypocotyl segments treated with oryzalin.

\begin{tabular}{ccccc}
\hline Treatment & Survival/treated $(\%)^{\mathrm{z}}$ & Diploid no. (\%) & Mixoploid no. (\%) & Tetraploid no. (\%) \\
\hline $0 \mu \mathrm{M}$ & $20 / 20(100) \mathrm{a}$ & $20(100) \mathrm{a}$ & $0(0) \mathrm{a}$ & $0(0) \mathrm{b}$ \\
$30 \mu \mathrm{M} 24 \mathrm{~h}$ & $10 / 20(50) \mathrm{b}$ & $9(90) \mathrm{abc}$ & $1(10) \mathrm{a}$ & $0(0) \mathrm{b}$ \\
$48 \mathrm{~h}$ & $9 / 20(45) \mathrm{b}$ & $7(67) \mathrm{d}$ & $2(22) \mathrm{a}$ & $1(11) \mathrm{ab}$ \\
$72 \mathrm{~h}$ & $11 / 20(55) \mathrm{b}$ & $8(73) \mathrm{bcd}$ & $3(27) \mathrm{a}$ & $0(0) \mathrm{b}$ \\
$60 \mu \mathrm{M} 24 \mathrm{~h}$ & $11 / 20(55) \mathrm{b}$ & $8(73) \mathrm{bcd}$ & $3(27) \mathrm{a}$ & $0(0) \mathrm{b}$ \\
$48 \mathrm{~h}$ & $10 / 20(50) \mathrm{b}$ & $6(60) \mathrm{d}$ & $4(40) \mathrm{a}$ & $0(0) \mathrm{b}$ \\
$72 \mathrm{~h}$ & $11 / 20(55) \mathrm{b}$ & $10(91) \mathrm{abc}$ & $1(9) \mathrm{a}$ & $0(0) \mathrm{b}$ \\
$90 \mu \mathrm{M} 24 \mathrm{~h}$ & $12 / 20(60) \mathrm{ab}$ & $7(58) \mathrm{d}$ & $5(42) \mathrm{a}$ & $0(0) \mathrm{b}$ \\
$48 \mathrm{~h}$ & $12 / 20(60) \mathrm{ab}$ & $7(58) \mathrm{d}$ & $5(42) \mathrm{a}$ & $0(0) \mathrm{b}$ \\
$72 \mathrm{~h}$ & $9 / 20(45) \mathrm{b}$ & $8(89) \mathrm{ab}$ & $1(11) \mathrm{a}$ & $0(0) \mathrm{b}$ \\
$120 \mu \mathrm{\mu} 24 \mathrm{~h}$ & $6 / 20(30) \mathrm{b}$ & $3(50) \mathrm{cd}$ & $1(17) \mathrm{a}$ & $2(33) \mathrm{a}$ \\
$48 \mathrm{~h}$ & $8 / 20(40) \mathrm{b}$ & $4(50) \mathrm{d}$ & $4(50) \mathrm{a}$ & $0(0) \mathrm{b}$ \\
$72 \mathrm{~h}$ & $7 / 20(35) \mathrm{b}$ & $4(57) \mathrm{d}$ & $2(29) \mathrm{a}$ & $1(14) \mathrm{ab}$ \\
\hline
\end{tabular}

${ }^{\mathrm{z}}$ Values containing the same letter within a column are not significantly different from each other at the $5 \%$ level of significance. possible enhanced action compared with colchicine. Supporting this supposition, a number of tetraploid plants were found in three of the oryzalin treatments (Table 2; Fig. 1C). The treatment producing the most tetraploids was a 24 -h duration in $120 \mu \mathrm{M}$ oryzalin with $33 \%$ of surviving explants being tetraploid. Despite explant survival being only $30 \%$ in this treatment, it is not so poor as to abandon it completely. Väinölä and Repo (2001) suggest that a concentration and duration of treatment that is highly lethal (low survival) may be an advantage because it reduces the number of diploid and mixoploid plants that need to be screened and tested when the target is tetraploids. However, care must be taken even with this approach because the tetraploids induced by high concentrations may have aberrations like a reduced growth rate. In addition to doubling meristematic cells, high concentrations could adversely affect surrounding nondividing tissues, thereby reducing the overall vigor of the explant.

In some explants exposed to colchicine or oryzalin for 48 or $72 \mathrm{~h}$, doubling of DNA content happened twice resulting in a plant containing diploid, tetraploid, and octoploid nuclei. In another individual, an intermediate peak between the diploid and tetraploid peak was observed (Fig. 1D). This peak, however, is unlikely to be triploid nuclei, because the peak is not equidistant from the diploid and tetraploid peak but appears to be of intermediate ploidy. Possibly, the oryzalin treatment caused a disruption in cell division in some of the cells such that DNA replication was not fully completed, leading to an incomplete doubling of the chromosomes and a plant that contains some sections/leaves of intermediate ploidy. Although uncommon, incomplete doubling and aneuploid and triploid production can occur when attempting to induce tetraploidy (Zlesak et al., 2005).

In this study, more mixoploids were induced, and very few tetraploids were observed in most of the treatments. Similarly, in Rhododendron, both colchicine and oryzalin produced more plants of mixed ploidy than stable tetraploids (Väinölä and Repo, 2001). In closely related Gladiolus, a high percent (42.9) of plantlets treated with $125 \mu \mathrm{M}$ colchicine were tetraploid with no mixploids induced (Suzuki et al., 2005). One explanation could be that multicellular tissue was used as the starting material in Watsonia compared with callus cultures (containing high numbers of individual cells undergoing rapid division) in Gladiolus. Thus, successful polyploid induction in Watsonia occurred in some cells and not in others. One possibility of improving this system is to use individual cells as starting material with the aim of producing a plant of only one ploidy level. Alternatively, additional concentrations and treatment times or sizes of explants could be evaluated because these can affect the percent of meristem cells successfully doubled and penetration of the chromosome-doubling agent, respectively (Allum et al., 2007). Most likely, penetration by the agent was through 
the cut end, and perhaps a method in which the entire explant is submerged (like in a liquid-shake culture) would improve penetration. It is possible to isolate complete polyploid sectors from mixoploid individuals eventually, but it may be simpler to discard these and produce stable tetraploids from scratch.

Watsonia plants take a number of years to produce a corm large enough to flower; thus, these tetraploid plants will have to be monitored until they flower to determine if altered ploidy level has any significant effect on plant height and flower morphology. Once flowering, fertility will need to be assessed to determine if barriers preventing seed production are present. Tetraploid plants in essence represent a new population with possibilities for epistatic interactions, and time will be needed to ensure genome stability. Superior genotypes with improved characteristics can then be selected for breeding purposes or micropropagated for commercial production and distributed to local nurseries.

\section{Literature Cited}

Allum, J.F., D.H. Bringloe, and A.V. Roberts. 2007. Chromosome doubling in a Rosa rugosa Thunb. hybrid by exposure of in vitro nodes to oryzalin: The effects of node length, oryzalin concentration and exposure time. Plant Cell Rep. 26:1977-1984.

Ascough, G.D., F. Bakos, B. Barnabás, and J. van Staden. 2006. Screening South African wheat germplasm for androgenic competence. S. Afr. J. Bot. 72:40-45.

Ascough, G.D., J.E. Erwin, and J. van Staden. 2007. In vitro propagation of four Watsonia species. Plant Cell Tiss. Org. Cult. 88:135145.

Ascough, G.D., J.E. Erwin, and J. van Staden. 2008. Reduced temperature, elevated sucrose, continuous light and gibberellic acid promote corm formation in Watsonia vanderspuyiae. Plant Cell Tiss. Org. Cult. (in press).

Berkov, S. and S. Philipov. 2002. Alkaloid production in diploid and autotetraploid plants of Datura stramonium. Pharm. Biol. 40:617-621.

Caperta, A.D., M. Delgado, F. Ressureiçáo, A. Meister, R.N. Jones, W. Viegas, and A.
Houben. 2006. Colchicine-induced polyploidization depends on tubulin polymerization in c-metaphase cells. Protoplasma 227:147153.

Chen, L.P., Y.J. Wang, and M. Zhao. 2006. In vitro induction and characterization of tetraploid Lychnis senno Siebold et Zucc. HortScience 41:759-761.

Cohen, D. and J.L. Yao. 1996. In vitro chromosome doubling of nine Zantedeschia cultivars. Plant Cell Tiss. Org. Cult. 47:43-49.

Contreras, R.N., T.G. Ranney, and S.P. Tallury. 2007. Reproductive behaviour of diploid and allotetraploid Rhododendron L. 'Fragrant Affinity'. HortScience 42:31-34.

De Carvalho, J.F.R.P., C.R. De Carvalho, and W.O Otoni. 2005. In vitro induction of polyploidy in annatto (Bixa orellana). Plant Cell Tiss. Org. Cult. 80:69-75.

De Jesus-Gonzalez, L. and P.J. Weathers. 2003. Tetraploid Artemisia annua hairy roots produce more artemisinin than diploids. Plant Cell Rep. 21:809-813.

Dolezel, J., S. Lucretti, and I. Schubert. 1994. Plant chromosome analysis and sorting by flow cytometry. Crit. Rev. Plant Sci. 13:275-309.

Ganga, M. and N. Chezhiyan. 2002. Influence of the antimitotic agents colchicine and oryzalin on in vitro regeneration and chromosome doubling of diploid bananas (Musa spp.). J. Hort. Sci. Biotechnol. 77:572-575.

Gao, S.L., B.J. Chen, and D.N. Zhu. 2002. In vitro production and identification of autotetraploids of Scutellaria baicalensis. Plant Cell Tiss. Org. Cult. 70:289-293.

Gmitter, F.G., X.B. Ling, C.Y. Cai, and J.W. Grosser. 1991. Colchicine-induced polyploidy in citrus embryogenic cultures, somatic embryos and regenerated plantlets. Plant Sci. 74:135-141

Goldblatt, P. 1980. Polyploidy in angiosperms, p. 219-239. In: Lewis, W.H. (ed.) PolyploidyBiological relevance. Plenum Press, New York, NY.

Goldblatt, P. 1989. The genus Watsonia. National Botanical Gardens, Kirstenbosch. p. 3-25.

Goldblatt, P., V. Walbot, and E.A. Zimmer. 1984. Estimation of genome size (C-value) in Iridaceae by cytophotometry. Ann. Mo. Bot. Gard. 71:176-180.

Griesbach, R.J. and R.N. Bhat. 1990. Colchicineinduced polyploidy in Eustoma grandiflorum. HortScience 25:1284-1286.
Jaskani, M.J., S.W. Kwon, and D.H. Kim. 2005. Comparative study on vegetative, reproductive and qualitative traits of seven diploid and tetraploid watermelon lines. Euphytica 145: 259-268.

Kadota, M. and Y. Niimi. 2002. In vitro induction of tetraploid plants from diploid Japanese pear cultivar (Pyrus pyrifolia N. cv. Hosui). Plant Cell Rep. 21:282-286.

Kim, Y.S., E.J. Hahn, H.N. Murthy, and K.Y. Paek. 2004. Effect of polyploidy induction on biomass and ginsenoside accumulations in adventitious roots of ginseng. J. Plant Biol. 47:356360.

Levin, D.A. 2002. The role of chromosomal change in plant evolution. Oxford University Press, New York, NY. p. 98-147.

Masterson, J. 1994. Stomatal size in fossil plants: Evidence for polyploidy in majority of flowering plants. Science 264:421-424.

Murashige, T. and F. Skoog. 1962. A revised medium for rapid growth and bio assays with tobacco tissue cultures. Physiol. Plant 15:473497.

Pringle, G.J. and B. Murray. 1992. Polyploidy and aneuploidy in the tamarillo Cyphomandra betacea (Cav) Sendt (Solanaceae). 2. Induction of tetraploidy, interploidy crosses and aneuploidy. Plant Breed 108:139-148.

Stanys, V., A. Weckman, G. Staniene, and P. Duchovskis. 2006. In vitro induction of polyploidy in Japanese quince (Chaenomeles japonica). Plant Cell Tiss. Org. Cult. 84:263268.

Suzuki, K., Y. Takatsu, T. Gonai, and M. Kasumi. 2005. Plant regeneration and chromosome doubling of wild Gladiolus species. Acta Hort. 673:175-181.

Thompson, D.I., N.O. Anderson, and J. van Staden. 2005. Watsonias as container plants: Using paclobutrazol for flowering and height control. S. Afr. J. Bot. 71:426-431.

Väinölä, A. and T. Repo. 2001. Polyploidisation of Rhododendron cultivars in vitro and how it affects cold hardiness. Acta Hort. 560:319322.

Zlesak, D.C., C.A. Thill, and N.O. Anderson. 2005. Trifluralin-mediated polyploidisation of Rosa chinensis minima (Sims) Voss seedlings. Euphytica 141:281-290. 